\title{
Caries Status of Children and Oral Health Behavior, Knowledge and Attitude of Their Mothers and Schoolteachers in Mathura City
}

Ramen Haloi, Navin Anand Ingle, Navpreet Kaur

\begin{abstract}
Aim: The study was undertaken to assess the caries status in children of 1 st (6 years) and 6th grade (12 years) and knowledge, attitude and practice (KAP) of mothers and schoolteachers in Mathura city.
\end{abstract}

Materials and methods: A total of 872 mothers, 140 schoolteachers, 500 children of grade I and 500 children of grade VI participated in the study. Clinical examinations of grades I and grade VI children were performed. Data on mothers and teachers were collected through personal interviews and selfadministered questionnaires respectively. Statistical significance was set at $p \leq 0.05$.

Results: At the age of 6 and 12, the mean decayed, missing and filled teeth (DMFT) index was 2.4 and 1.3 respectively. Mothers showed a fair level of knowledge (74.9\%) and favorable attitude $(70.6 \%)$, while maximum schoolteachers showed a good level of knowledge (67.9\%) and favorable attitude (57.1\%) toward oral health. Schoolteachers, dentists and television were found to be the most important source of dental health information among the schoolteachers and mothers.

Conclusion: It is concluded from the study that oral health knowledge of mothers and teachers were found to be fair and good respectively. The schoolteachers knew about the poor dental conditions in children and wanted to become involved in oral health education. Training of the teachers should aim at improving their level of knowledge on oral health.

Keywords: Knowledge, Attitude, Oral health behavior, Dental caries.

How to cite this article: Haloi R, Ingle NA, Kaur N. Caries Status of Children and Oral Health Behavior, Knowledge and Attitude of Their Mothers and Schoolteachers in Mathura City. J Contemp Dent 2012;2(3):78-83.

Source of support: Nil

Conflict of interest: None declared

\section{INTRODUCTION}

Many industrialized countries have experienced a decline in dental caries prevalence among children over the past decades. ${ }^{1,2}$ Against this, increasing levels of dental caries have been found in some developing countries, especially for those countries where preventive programs have not been established. ${ }^{3-5}$ In order to control the growing burden of oral diseases, a number of developing countries recently introduced school-based oral health education and preventive programs which aim at improving oral health behavior and status of the child population. ${ }^{6,7}$
India, a developing country, faces many challenges in rendering oral health needs. The majority of Indian population resides in rural areas, of which more than $40 \%$ constitute children. These children cannot avail dental facilities due to inaccessibility, financial constraints and stagnation of public dental health care services. This entails the health professional to adopt a more practical approach to achieve prevention of oral diseases. ${ }^{8,9}$

To promote oral health, oral health education for children is considered a priority because of the caries high risk at this age, as well as the constant changes in oral environment, the facility for changing bad habits and provision of higher facility for learning. Educating the children, because of its coverage, is important for the concretization of health promotion actions directed to the improvement in children's skills, for making decision favorable to community, for the creation of healthy environment and consolidation of public politics for the quality of life. ${ }^{10}$

Schoolteachers and parents, especially mothers, are considered to be an important target group for various health educational activities with the underlying objective of inculcating healthy lifestyle practices into children for a lifetime. ${ }^{9}$ Schoolchildren in their early years involve 'Primary socialization' during which the earliest childhood routines and habits are acquired. ${ }^{11,12}$ These include dietary habits and healthy behaviors established as norms in the home and are dependent on the knowledge and behavior of parents and elder siblings. Studies have reported that poor attitude of parents toward oral health of young children are associated with increased caries prevalence. ${ }^{12,13}$ On the contrary, studies have also shown that the more positive is the parents' attitudes toward dentistry the better will be the dental health of their children. ${ }^{12-14}$

By virtue of their training and opportunity to influence large numbers of children and their parents, teachers form a group of particular interest in the planning and implementation of oral health preventive programs. ${ }^{15}$ Increasing the oral health knowledge of primary schoolteachers provide an opportunity to educate their students that has access to large populations of young people. Teachers cannot assist in developing well-informed students, if they themselves remain misinformed. Thus, the schoolteachers need to be enabled for the task in terms of 
improving their deficient knowledge on oral health and relative effectiveness of measure to prevent various oral problems. ${ }^{16}$ Inadequate knowledge, skills and motivation for teachers and mothers to provide oral health education has shown unfavorable repercussions on children's' oral health. ${ }^{17}$ A very few literatures and records were found which shows the influence of teachers and mothers oral health behavior, knowledge and attitude on their children's dental caries status. Keeping all these points in view, a study was undertaken to assess the caries status of children and oral health behavior, knowledge and attitude on their mothers and schoolteachers in Mathura city.

\section{AIMS AND OBJECTIVES}

1. To assess the caries status of 1 st (6 years) and 6 th grade (12 years) schoolchildren.

2. To assess the oral health behavior, knowledge and attitude of their mothers and schoolteachers.

3. To determine the source of information regarding oral health of mothers and schoolteachers.

4. To assess the health-promoting role of schoolteachers.

\section{MATERIALS AND METHODS}

An epidemiologic survey was conducted to assess the caries status in children of 1st (6 years) and 6th grade (12 years) and oral health behaviors, knowledge and attitude of mothers and schoolteachers in Mathura city.

\section{Source of Data}

According to the list obtained from Basic Shiksha Adhikaari office, there were a total of 7,000 schoolchildren of grade I and grade VI among the 125 private schools present in Mathura city. ${ }^{18}$ Prior to the survey informed consent was obtained from each study subjects. Data was collected through a clinical examination of schoolchildren of grade I (6 years) and grade VI (12 years) of private schools of Mathura city. Moreover, the study comprised the mothers of the schoolchildren $(n=872,86.3 \%$ response rate) who responded to a structured interviews. Finally, the study comprised the teachers of the 20 private schools and the total of 140 schoolteachers (response rate 100\%) responded to self-administered questionnaire.

\section{Inclusion Criterion}

- All the available schoolchildren of 20 private schools of Mathura city who were in grade I (6 years) and grade VI (12 years) were included in our study.

- Mothers and schoolteachers of the grade I (6 years) and grade VI (12 years) who were in the age range of 15 to 64 years and willing to participate in the survey.

\section{Exclusion Criterion}

- Subjects not willing to participate in the survey and those who were absent on the day of examination.

- Subjects suffering from major systemic illness.

\section{Sampling Methodology}

Based on the prevalence obtained for dental caries in children of age 6 to 12 years, it was necessary to take 925 as the minimum sample size. A slightly higher sample size of 1,000 was selected to compensate for any kind of permissible error and to increase the accuracy of the study. Mathura city was divided into five geographical zonescentral, North, South, East and West. In order to cover the total sample size of 1,000, 200 schoolchildren from each of the five zones were randomly selected out of which 100 children were from grade I (6 years) and 100 children were from grade VI (12 years). A total of 20 private schools participated in the study.

Mothers of all 1,000 schoolchildren were asked to attend a structured interview. A total of 872 mothers (response rate $\mathbf{8 6 . 3 \% )}$ ) responded to structured interviews. All interviews were undertaken in the schools, and the mothers were not informed about the professional background of the interviewer. The questions concerned oral health knowledge, attitudes, sources of oral health information, oral health behavior of the child and mother, parental support in oral health, evaluation of the dental health of their child, number of children in the family and educational level of the parents. Oral health knowledge and attitudes were measured by using positive and negative responses and 5-point Likert scale to the loaded statements. The validity and the reliability of the items have been tested in a previous methodologic study. ${ }^{19}$

From those 20 private schools, a total of 140 schoolteachers responded to self-administered questionnaires (response rate $100 \%)$. Identical structured questions on knowledge and attitudes were given to teachers and mothers but in case of schoolteachers additional structured questions were added related to their role in health promotion.

\section{Statistical Analysis}

The collected data was entered in the Microsoft excel sheet and analyzed using the SPSS, version 17.0 statistical package. Level of significance (p-value) was fixed at $0.05 \%$. The $\chi^{2}$ test was applied for the statistical evaluation of proportions and Student's t-tests were performed for the comparison of means.

\section{RESULTS}

The results of the study have been depicted in Figures 1 to 4 and Tables 1 to 4 . 
Most of the study subjects of both schoolteachers and mothers were distributed in the age group of 31 to 40 years (Fig. 1). The source of dental health information for schoolteachers and mothers are illustrated in Figure 2.

\section{Dental Caries}

The mean caries experience is given in Table 1 and it is shown that the d/D component constituted most of the caries indices. No significant differences in the caries indices were found by sex, however, the figures were higher in males than females in grade I. On the other hand the mean caries experience of the females were higher as compared to males of grade VI children $(\mathrm{p}<0.05)$. Table 2 presents the distribution of children by absolute value of caries index according to school grade, and Table 3 shows the distribution of children by caries severity zones.

\section{Knowledge and Attitudes of Mothers}

Maximum mothers, i.e. $74.9 \%$ showed fair knowledge followed by a portion, i.e. $25 \%$ showed good knowledge regarding oral health. A significant proportion of mothers, i.e. $70.6 \%$ showed favorable attitude toward oral health (Figs 3 and 4). Oral health knowledge of mothers has been correlated with level of education, age and number of children, a highly statistically significant correlation was found between oral health knowledge of mothers with all the three variables mentioned above ( $\mathrm{p}$-value is 0.000 ).

\section{Knowledge and Attitudes of Schoolteachers}

Maximum schoolteachers, i.e. $67.9 \%$ showed good knowledge followed by a portion, i.e. 32.1\% showed fair knowledge regarding oral health. A significant proportion of schoolteachers, i.e. 57.1 and $42.9 \%$ of the schoolteachers showed favorable and most favorable attitudes toward oral health (Figs 3 and 4). A highly statistically significant correlation was found between oral health knowledge and gender (p-value is 0.000 ). No statistically significant relation was found when oral health knowledge was compared with level of education (p-value is 0.74). When attitudes of the schoolteachers were correlated with level of education and gender, a highly significant correlation was found between gender and attitude of the schoolteachers (p-value is 0.000 ).

\section{Oral Health Habits}

Maximum number of study subjects both from schoolteachers and mothers, i.e. 64.3 and $47.6 \%$ respectively had visited the dentist whenever they had dental problems. Almost equal proportion of study subjects from both the groups had seen a dentist within the past 12 months. All the schoolteachers, i.e.100\% revealed that they brushed their teeth with toothbrush and toothpaste, while $99.5 \%$ of mothers revealed the same. A significant proportion, i.e. $72 \%$ of mothers brushed once daily while maximum schoolteachers answered that they brushed their teeth at least twice a day.

\section{Role of Teachers in Promoting Oral Health}

Respondents were asked to indicate the extent of their agreement or disagreement with statements of responsibilities that are sometimes expected of schoolteachers. A scale ranging from strongly agree to strongly disagree was used and then collapsed to agree/disagree. Respondents were most likely to accept responsibility for roles that did not involve loss of class time by students, out of school efforts, or direct supervision. In particular, the latter category was

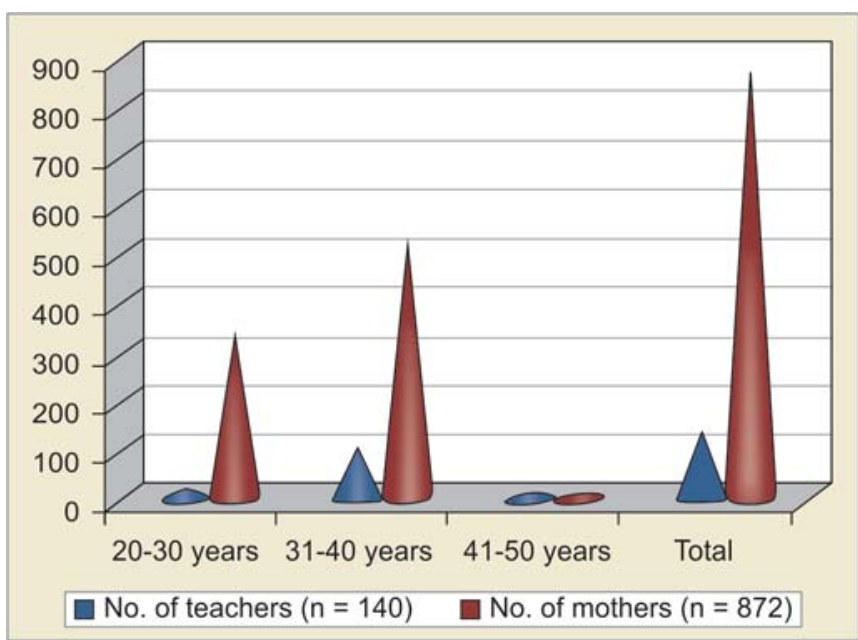

Fig. 1: Distribution of the study subjects according to age among schoolteachers and mothers

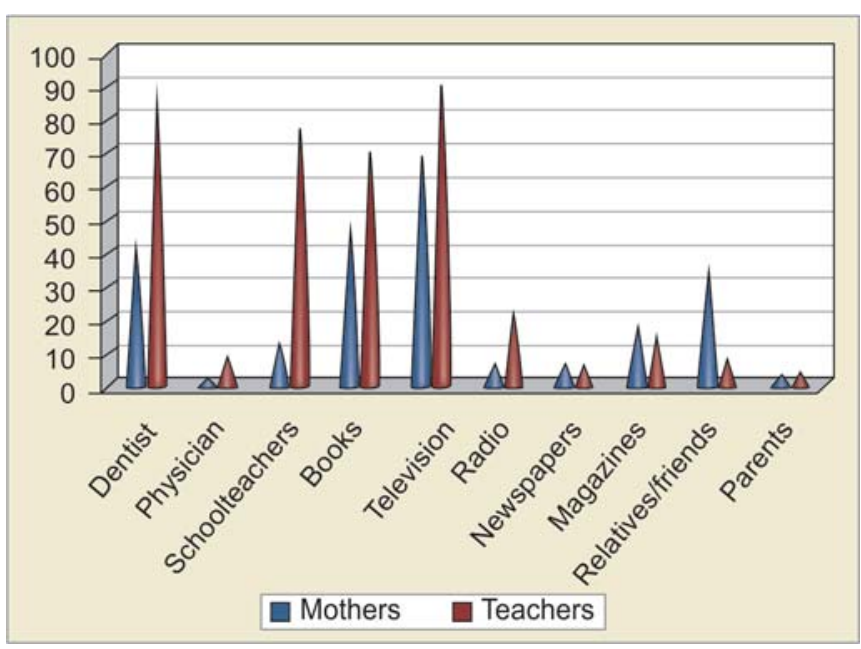

Fig. 2: Distribution of the study subjects according to source of dental health information 
not considered by respondents to be a responsibility of teachers (Table 4).

\section{DISCUSSION}

The interview method was chosen for the study of the mothers since, many of these were not familiar with the questionnaire surveys. Due to practical and economical reasons the data on the schoolteachers were collected by means of self-administered questionnaires. Acceptable response rates were obtained for both data sets. In order to control the reliability, highly structured questionnaires were created and the wording of the questions to mothers and teachers was identical to ensure valid comparisons of the responses. Besides the pilot study, the methodology of the questionnaires had been assessed in previous studies. $^{19}$

\section{Source of Dental Health Information of Mothers and Schoolteachers}

In our study, television, dentist and schoolteachers were found to be the most frequently reported source of dental health information among both mothers and schoolteachers.
These results were in accordance with the previous studies conducted by Petersen et al, ${ }^{5}$ Elena et al, ${ }^{20}$ Lang et al. ${ }^{21}$

\section{Caries Status of Schoolchildren}

This study showed that at the age of 6 and 12, the mean decayed, missing and filled teeth (dmft/DMFT) index was 2.4 and 1.3 respectively. These findings were in agreement with previous surveys of 12 -year-old which had shown the mean DMFT at 1.1 to $1.9 .^{22-25}$ Our study results were much lower than a previous study conducted by Bondarik Elena, they had found a mean DMFT of 2.7 in 12 years old children in Belarus. ${ }^{20}$

\section{Dental Knowledge of Mothers and Schoolteachers}

The knowledge regarding oral health of mothers and schoolteachers seemed to be diffused. On the one hand, significant proportions of the mothers knew about the role of bacteria and sugar in dental caries, on the other hand, the level of knowledge was low with regard to the effect of hidden sugar and fluoride. These study results were in

\begin{tabular}{lcccc}
\hline & \multicolumn{2}{c}{ Table 1: Dental caries experience of grade I and grade VI children according to gender } \\
\hline Dental caries index & \multicolumn{2}{c}{ Grade I $(n=500)$} & \multicolumn{1}{c}{ Grade VI $(n=500)$} \\
& Male & & Female & Male \\
\hline Decayed (d) & 3.3 & 2.59 & - & - \\
Missing (m) & 0.02 & 0.02 & - & - \\
Filled (f) & 0.02 & 0.02 & - & - \\
Total DMFT & 3.4 & 2.64 & 0.76 & 0.93 \\
Decayed (D) & - & - & 0 & 0.05 \\
Missing (M) & - & - & 0.19 & 0.46 \\
Filled (F) & - & - & 0.96 & 1.45 \\
Total DMFT & - & - & & - \\
\hline
\end{tabular}

\begin{tabular}{llcccc}
\multicolumn{5}{c}{ Table 2: Distribution in percentage according to absolute value of dental caries index by school grade/age } \\
\hline Grade & Sex & 0 & $1-4$ & $5-8$ & $9-12$ \\
I (primary teeth) & Male & $18.8 \%$ & $54.4 \%$ & $24.4 \%$ & $2.4 \%$ \\
\multirow{2}{*}{ VI (permanent teeth) } & Female & $26 \%$ & $56.8 \%$ & $15.6 \%$ & $1.6 \%$ \\
& Male & $67.1 \%$ & $29.7 \%$ & $3.2 \%$ & 0 \\
\hline
\end{tabular}

\begin{tabular}{|c|c|c|c|c|}
\hline \multirow[t]{2}{*}{ Caries severity zones } & \multicolumn{2}{|c|}{6 years (primary teeth) } & \multicolumn{2}{|c|}{12 years (permanent teeth) } \\
\hline & Male & Female & Male & Female \\
\hline Zone 1 (caries free) & $18.8 \%$ & $26 \%$ & $67.1 \%$ & $43.9 \%$ \\
\hline $\begin{array}{l}\text { Zone } 2 \text { (caries in pits/fissures in } \\
\text { molars/premolars) }\end{array}$ & $5.2 \%$ & $8.7 \%$ & $21.5 \%$ & $40.5 \%$ \\
\hline $\begin{array}{l}\text { Zone } 3 \text { (caries in approximal surfaces of } \\
\text { canines/premolars/molars) }\end{array}$ & $18.1 \%$ & $20.3 \%$ & $2.1 \%$ & $4.2 \%$ \\
\hline smooth surfaces) & $57.9 \%$ & $45 \%$ & $9.3 \%$ & $11.4 \%$ \\
\hline
\end{tabular}




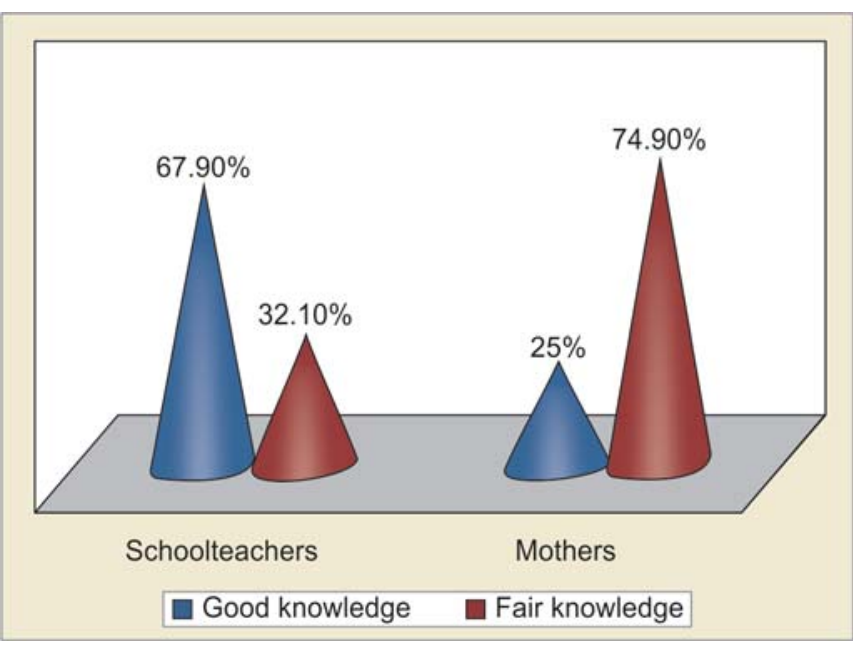

Fig. 3: Distribution of the study subjects according to knowledge score among schoolteachers and mothers

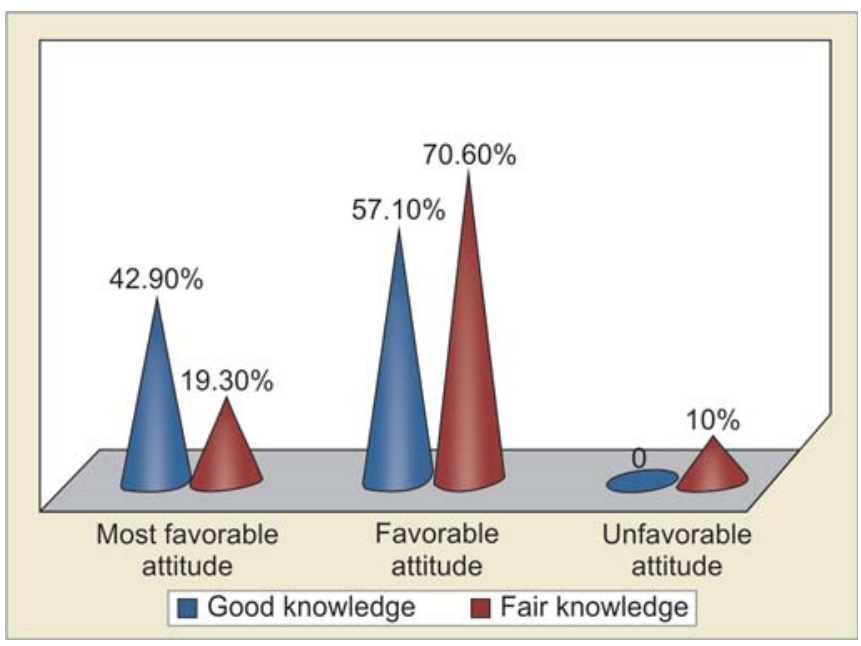

Fig. 4: Distribution of the study subjects according to attitude score among schoolteachers and mothers

Table 4: Perceived role of teachers in promoting oral health

Teachers should

Should refer students with dental problems to the dentists

Advice students regarding advertising of commercial sugar products

Instruct students about scientifically valid methods to prevent oral diseases

Allow class time for students to get dental care

Be actively involved in community efforts to improve students' oral health

Supervise daily brushing and flossing in the classroom
Agree

$93.6 \%$

$72.9 \%$

$88.6 \%$

$45 \%$

$60 \%$

$12.1 \%$
Disagree

$6.4 \%$

$17.1 \%$

$11.4 \%$

$55 \%$

$40 \%$

$87.9 \%$ accordance with the previous studies conducted by Petersen et al, ${ }^{5}$ Elena et al, ${ }^{20}$ Lang et al. ${ }^{21}$

\section{Attitudes Toward Oral Health of Mothers and Schoolteachers}

Both the mothers and the schoolteachers showed positive attitudes toward prevention and the study indicates that various sources would seem available and effective for oral health information. Studies conducted by Ramen et al and Pankaj et $\mathrm{al}^{26}$ had found that the majority of the study subjects had favorable attitude toward oral health which was in accordance with our study results.

\section{Oral Health Behavior of Mothers and Schoolteachers}

No significant difference in views was found between mothers and schoolteachers regarding oral health behaviors. The survey showed a clear discrepansy between dental knowledge and practice, which was in accordance with the previous studies conducted by Petersen et al, ${ }^{5}$ Elena et al, ${ }^{20}$ and Lang et al. ${ }^{21}$

\section{Health-promoting Role of Schoolteachers}

Respondents were more likely to accept responsibility for roles that did not involve loss of class time by students, out-of-school efforts or direct supervision. In particular, the latter category was not considered by respondents to be a responsibility of schoolteachers. This confirms the observation of other investigators. ${ }^{27,28}$

However, the data collection methods may have certain limits. With respect to dental knowledge, oral hygiene habits and frequency of dental visits, over-reporting may be assumed whereas under-reporting has to be considered with regard to the consumption of sugar, sweets and sugary drinks.

\section{CONCLUSION}

The study concluded that there were no significant differences in the level of oral health knowledge between mothers and schoolteachers, even though the teachers tended to have been informed more often by dentists. Both mothers and schoolteachers showed positive attitudes toward prevention, and the study indicates that various sources would seem available and effective for oral health information. The results showed disparity between dental knowledge and oral health practices of both mothers and schoolteachers. The teachers responded positively to becoming involved in the oral health education of the children, and they can be undoubtedly become key persons in this activity. However, they need proper training and practical support from dentists experienced in public health, and the teachers should also be provided with educational materials. By providing suitable educational materials and 
by engaging in health promotional activities, dental public health professionals can interact with schoolteachers in a mutually beneficial manner.

\section{REFERENCES}

1. Marthaler TM, O’Mullane D, Vrbic V. The prevalence of dental caries in Europe 1990-95. Caries Res 1996;30:237-55.

2. Burt BA. Trends in caries prevalence in North American children. Int Dent J 1994; 44:403-13.

3. Sheiham A. Changing trends in dental caries. Int J Epidemiol 1984;13:142-47.

4. Petersen PE, Razanamihaja N. Oral health status of children and adults in Madagascar. Int Dent J 1996;46:41-47.

5. Petersen PE, Esheng Z. Dental caries and oral health behavior situation of children, mothers and schoolteachers in Wuhan, People's Republic of China. Int Dent J 1998;48:210-16.

6. Petersen PE, et al. Effect of a school-based oral health education programme in Wuhan city, Peoples Republic of China. Int Dent J 2004;54:33-41.

7. George B, John J, Saravanan S, Arumugham IM. Oral health knowledge, attitude and practices of schoolteachers in Chennai. JIAPHD 2010;15:85-90.

8. Thomas S, Tandon S, Nair S. Effect of dental health education on the oral health status of a rural child population by involving target groups. J Indian Soc Pedod Prev Dent 2000 Sep;18(3): 115-25.

9. Raj SM, Prasad KVV, Javali SB. Factors affecting the knowledge on prevention of oral diseases among schoolteachers of Dharwad city: A survey from India. Webmed Central Dent 2011;2(2):4-13.

10. Garbin CAS, Garbin AJI, dos Santos KT, Lima DP. Oral health education in schools: Promoting health agents. Int J Dent Hygiene 2009;7:212-16.

11. Holm AK. Caries in preschool children: International trends. Int J Dent 1990;18(6):291-95.

12. Suresh BS. Mothers' knowledge about pre-school child's oral health. JISPPD 2010;28(4):282-87.

13. Hinds K, Gregory JC. National diet and nutrition survey: Children aged $1 \frac{1}{2}$ to $4 \frac{1}{2}$ years. Vol 2: Report of dental survey. London: HMSO, 1995.

14. Friedman LA, Mackler IG, Hoggard GJ. A comparison of perceived and actual needs of a selected group of children in Texas community. Dent Oral Epidemiol 1976;4:89-93.

15. Astrom AN, Jackson W, Mwangosi IE. Knowledge, beliefs and behavior related to oral health among Tanzanian and Ugandan teachers trainees. Acta Odontol Scand 2000;58:11-18.

16. Pai V, et al. Dental awareness among Kannada and English medium primary schoolteachers in Mangalore city. JIAPHD 2006;7:7-12.
17. Mwangosi IE, Nyandindi U. Oral health related knowledge, behaviors, attitudes and self-assessed status of primary schoolteachers in Tanzania. Int Dent J 2002;52:130-36.

18. Basic Shiksha Adhikari, Department of Education, Dholi Pyau, Mathura.

19. Petersen PE. Guttman scale analysis of dental health knowledge and attitudes. Comm Dent Oral Epidemiol 1989;17:170-72.

20. Elena B, Petr L. Oral health and children attitudes among mothers and schoolteachers in Belarus. Stomatologija-Baltic Dent Maxillofacial J 2004;6:40-43.

21. Lang WP, Woolfolk MW, Faja BW. Dental health knowledge and attitudes of elementary schoolteachers in Michigan. J Public Health Dent 1989;49:44-50.

22. Li G, Wang C, Li J, Ai Y. Dental caries in Yanan schoolchildren aged 12 years: China. Comm Dent Oral Epidemiol 1989; 22:208.

23. Hu DY, Liu DW. Trends of caries prevalence and experience in children in Chengdu City, West China,1982-90. Comm Dent Oral Epidemiol 1992;20:308-09.

24. Shi Y, Barmes D, Bratthall D, et al. WHO pathfinder caries survey in Beijing extended with data for prevalence of mutans streptococci. Int Dent J 1992;42:31-36.

25. Petersen PE, Guang LX. Dental caries prevalence in a group of schoolchildren in Wuhan City, PR China. Comm Dent Oral Epidemiol 1994;22:465-66.

26. Sehgal P, Ankola A, Nagesh L, Hegde P. Knowledge, attitude and practices towards oral health among Anganwadi workers of Belgaum city, Karnataka. JIAPHD 2005;5:14-16.

27. Loupe MJ, Frazier PJ. Knowledge and attitudes of schoolteachers toward oral health programs and preventive dentistry. J Am Dent Assoc 1983 Aug;107:229-34.

28. Boyer ME. Classroom teachers' perceived role in dental health education. J Public Health Dent 1976;36:237-43.

\section{ABOUT THE AUTHORS}

\section{Ramen Haloi (Corresponding Author)}

Postgraduate Student, Department of Public Health Dentistry KD Dental College and Hospital, Mathura, Uttar Pradesh, India e-mail: drramenhaloi@gmail.com

\section{Navin Anand Ingle}

Professor and Head, Department of Public Health Dentistry, KD Dental College and Hospital, Mathura, Uttar Pradesh, India

\section{Navpreet Kaur}

Senior Lecturer, Department of Public Health Dentistry, KD Dental College and Hospital, Mathura, Uttar Pradesh, India 